\title{
12
}

\section{Means and Meanings of Research Collaboration in the Face of a Suffering Earth: A Landscape of Questions}

\author{
Birgit Schaffar and Eevi E. Beck
}

\section{Introduction: Where on Earth Are We?}

If the authors of this chapter were to enter a plane to visit each other, we would contribute to a problem. Yet, at times we have been tempted, as it probably would strengthen our collaboration. How to evaluate these different impulses or needs? When considering whether to book a flight to visit an academic collaborator, or whether to offer the next conference on campus or online, we are entering a landscape of practical, technical and ethical considerations with competing concerns. As flying contributes to climate change, extensive flyers-which include most academics-contribute more. Most academics we know have substantial individual choice

B. Schaffar $(\bowtie)$

University of Helsinki, Helsinki, Finland

e-mail: birgit.schaffar@helsinki.fi

E. E. Beck

University of Oslo, Oslo, Norway

e-mail: e.e.beck@iped.uio.no 
about how much to fly. If as academics we have long ignored the impacts of our travelling habits, this is no longer a tenable position.

Changing our work habits as scholars is necessary, but is this only an individual question? To address this, we need an understanding of the present situation. Seeing the complexity of the current situation can be insightful and helpful for acting on the awareness that comes from it. The task is explorative, non-exhaustive and urgent.

Starting from the urgency of changing academics' habits of travel, the chapter suggests a direction by first exploring the basics of where we are now. Can/should we stop collaborating over distance? This raises the issue of what academic collaboration is for, which is explored in the next section. Could we stop travelling but continue distance collaboration simply by switching to video conferencing? The following section discusses this by raising issues about the meanings of physical presence, the possibilities and limitations of technological mediation and new ethical liabilities introduced by their usage. These two aspects- the meaning of collaboration and the means of collaboration-open questions about understanding academic responsibility for the Earth.

While the option of flying is as recent as a few decades old, considering the ethical consequences of scholarship is not. This was part of the conceptualisation of the university already around the turn of the eighteenth to nineteenth centuries. Drawing on the initial thoughts about establishing a university in Berlin by von Humboldt, Schleiermacher and Fichte, we consider their conceptualisation of independent and high-quality academic work-Erkenntnis, which we translate as scholarship-and why academic collaboration across distance matters. In that, this chapter builds on the continental tradition of conceptualising what universities are for. Taking responsibility in and for society is in this tradition an aspect of academic life. How to take responsibility, however, is intensely situated in time and place, as is where to draw the boundaries ('how broad?', 'how much responsibility?' etc.). Answers to these questions are contested and subject to debate.

In considering how to act, commitment to change can be based on either individual ('I want to reduce my carbon footprint') or collective (developing a culture for prioritising low-impact forms of collaboration) perspectives. Both are needed, and further, they are not as separate as may 
appear at first sight. Thus, in our discussion, both are encompassed. The technology-intensive character of contemporary (academic) life adds layers of complexity to research collaboration. Simplified notions of the roles that geography, embodied presence and technical mediation playspecifically ideas that distance is unimportant and mediation is neutraldownplay the complexities of the ethical questions we face daily. The argument therefore turns to socio-material analysis to reopen this aspect of the complexity of the means of collaboration.

Exploring whether and how to take responsibility helps us reflect on the landscape and the many positionings possible to take within it. Following that, we then propose a set of questions that bring the complexities nearer to daily life and ask how to change habits. This includes 'sticky' issues such as challenging established hegemonies.

Throughout the chapter, we (the authors) explore matters which strongly implicate our own collaboration. To us, the multidimensional complexity of the issue(s) requires helpful metaphors to think with. We are sketching a landscape of questions, in which general directions and signposts coexist with the need to develop specific responses to specific situations. The direction we indicate is towards taking responsibility for the broader impact on society and on the Earth, not only what we research but also how. What might be encountered at first as practical questions of whether to travel, opens a landscape of intertwined issues of where and how to take responsibility, and how to imagine alternatives. One signpost along the way is that collaboration and a concern for a greater good than individual interests are part and parcel of scholarship. Another signpost is that academic collaboration cannot simply be transferred online without further ado, as argued in the section thereafter. Rather, we need to rethink what research collaboration is for and develop tools suited for that purpose.

The concluding section of the chapter broadens the perspective and suggests that an ethics of collaboration is needed. This includes a commitment to taking responsibility_for each other as colleagues, for the society and for the Earth. While as academics, many of us may be habituated into staying with analyses and understanding, taking action is now required of us based on insight into the current and future suffering we are presently contributing to. 


\section{The Importance of Academic Collaboration and Expertise (Erkenntnis)}

Should academics collaborate? And if so, why over distance? To explore these questions, we first consider what we mean by academic, including what distinguishes (academic) scholarship from other forms of 'knowledge' or 'expertise', the role of universities in society, and how scholarship is passed on (i.e. how academic communities recognise and promote achievement). To examine these issues, we draw on Fichte's (1807 [2010]), Schleiermacher's (1808 [2010]) and von Humboldt's (1809 [2010a], 1810 [2010b]) ideas about the university and scholarship. Their work led to the establishment of the higher educational system in Prussia, often now referred to as von Humboldt's notion of the university (Schaffar \& Uljens, 2015). Aspects of their thinking on academic institutions have been the bedrock of universities as commonly conceptualised today (including the formation of a number of academic disciplines). Less well known are their thoughts on taking ethical responsibility and the importance of research collaboration.

In 1826, Schleiermacher expressed the sentiment of his time, with all the optimism for what scientific knowledge could bring to political and social life when he introduced his theory of education: 'There is nothing that could settle a dispute better than knowledge' (Schleiermacher, 1826 [1994], p. 170). What he had in mind, though, is not generally what we are inclined to think of as scientific knowledge today. The German term Erkenntnis establishes a broad conception of knowledge, explicitly not limited to narrow factual knowledge about a specific subject. The university should be a site not only for accumulating factual knowledge but should strive to be eine Schule der Kunst des wissenschaftlichen Verstandesgebrauchs (a school for the art of using the faculty of the mind) (Fichte, 2010, p. 14). This is because knowing implies responsibility for what we do with that knowledge (how we apply it etc.); knowledge and its application are not separate.

In Schleiermacher's sense, Erkenntnis has two aspects of particular relevance to our discussion. One is that the outcome of a research process is the culmination of a scholar striving for a sufficiently detached stance to 
establish conclusions that are consistent with the findings of the research. This is important to prevent academic claims from becoming only opinions or being shaped by power structures such as ideologies, propaganda or totalitarian manipulations of the truth. The other is that Erkenntnis includes the ability to critically assess and evaluate complex situations with integrity that is devoted to striving for truth, for humanity and for the common good (Schleiermacher, 1994). Being (academically) educated in this sense has a deeper meaning than having factual knowledge and the capacity to instrumentally apply it towards a given end (Schaffar \& Uljens, 2015).

In writings by von Humboldt and his contemporaries Schleiermacher and Fichte, Erkenntnis is developed as an essential aspect of establishing human communities, and as the source and result of human striving for enlightenment and moral maturity. These ideas are a reminder that academics' various ways of knowing (despite_or because of — their being continuously contested within the academic community) have value beyond the advancement of a discipline. Broader reasons to undertake academic research may not always surface, but they do exist: The human enlightenment and moral maturity of those days can be rethought now. For example, we need to awaken the role of stringent academic research in alerting people across the globe to the scale and urgency of the depletion of nature and its dire implications for humans and non-humans alike, and we need to go beyond academic methodology and face our own responsibilities as contributors to the problem. Collaboration to address these issues may include opening our hearts and minds, and our sense of ethics, to non-human messengers, ${ }^{1}$ as well as the insights of nonacademic humans.

Throughout the Western academic tradition, different circumstances and arguments have been given for why scholarly/academic expertise should be maintained and available in different places. One of the most obvious reasons why scholarship matters is its usefulness. Societies depend on the development of applicable technical solutions to challenges in their industries and various ways of thinking about and understanding challenges in communities. Besides its usefulness in terms of concrete instrumental outcomes, Schleiermacher argued that the education of scholars is a necessary effort to provide (democratic) states with educated 
civil servants (Schleiermacher, 2010, p. 129). Civil servants in democratic societies should not just be familiar with and follow the rules of any given political, clerical or economic power. Rather, knowledge is always placed in specific circumstances, with specific challenges and questions that require educated, professional consideration and judgement (Schleiermacher, 2010, pp. 126, 129; Fichte, 2010, p. 25; Schaffar \& Kronqvist, 2017). ${ }^{2}$ What should be done in particular situations cannot be derived from facts alone. Indeed, facts should be considered in their different modalities: What can be done with what we know versus what should be done? What are we obliged to do and what do we want to do? What ought we to strive for? (e.g. Murdoch, 1997, p. 299). When applying factual knowledge, therefore, there is a need for the specific ability that characterises scholarship: To be able to question and reason with the knowledge at hand, and about our aspirations. Are our aims consistent with some higher conception of truth, justice and a universal good, or are they a means for other, private, local or personal aims? As von Humboldt has pointed out, scholarship is a basic condition for the high demands of democratic structures in free societies (von Humboldt, 2010a, 2010b).

In using the term scholarship, we refer to the specific 'cultures of knowing' characteristic of academic research. It refers to an ability that is developed in specific situations, including through institutionalised processes of education or training, for which structures of formal recognition exist. While the debate flourishes among academics as to how to do this well, academic research and its insights/knowledges constitute forms of expertise that differ from other forms and are recognisable as such. Further, they are specific, situated and themselves imbued with power issues; they structure the conditions for entering academia and ultimately control access to academic knowledges. ${ }^{3}$ In this respect, it is fundamental to scholarship (Erkenntnis) that it remains a characteristic of the academic community.

Developing, maintaining, living and expressing Erkenntnis requires contact between scholars. Erkenntnis can be located and accumulated at certain sites-that is universities-where academics can collaborate locally and also between such sites - that is over distance-to critically inspire each other. Researchers need to actively work together and have a lively intellectual exchange with other scholars, in order to realise 
Erkenntnis-aus Liebe zur Kunst [der Erkenntnis] (out of love for the art of knowing), with consequences for society such as the flourishing of a sense of freedom (Fichte, 2010, p. 26; Schleiermacher, 2010, p. 131; von Humboldt, 2010a, p. 229).

Von Humboldt, Schleiermacher and Fichte developed their thought for the practical application of founding a model for the University of Berlin and other universities in Prussia. This included attention to Prussia's diplomatic position relative to the other small German states at that time. They argued that nationally financed universities should not try to limit their scholars to attend solely to the interests of their own countries and universities (cf. Schleiermacher, 2010, p. 132; von Humboldt, 2010a, p. 231). On the one hand, they heeded that states and societies may have their own national interests, that is developing advanced technical and social solutions. On the other hand, they paid critical attention to the competitive relations between countries, and through them also the universities of the time. They foresaw that countries and universities would be trying to attract the most influential scholars, develop the more successful inventions and so on, which in turn would appeal to the best scholars from other countries, encouraging them to move and improve academic clusters in opposition to other universities. According to von Humboldt, Schleiermacher and Fichte however, although Erkenntnis might be embedded in local circumstances, financed by certain national or private investors with their own interests, scholars should be fully free to cross national and institutional borders and to share their expertise and knowledge with colleagues from other universities and countries without competitive concerns. Erkenntnis should remain committed to the service of humankind, and for this reason, the idea of ownership of knowledge was highly problematic (Schleiermacher, 2010, p. 133; Fichte, 2010, p. 26).

Reading today, von Humboldt's, Schleiermacher's and Fichte's thoughts on the role of the institution of the university in serving a greater good reminds us that academics have a responsibility beyond their own subject interests, independent of the institutions they are working in and outside the scope of competitive interests connected to academic results. Institutions serve numerous purposes_cultural, geographic, administrative, and so on-but when the purpose of scholarship is considered to be 
working for humanity, the sense of responsibility applies to all disciplines and all scholars. While extending personal responsibility beyond one's own discipline is often considered an optional extra to the 'real work' of scholars, something of marginal significance to their core activity, this approach is no longer sufficient. The magnitude of issues facing humanity today means scholars have a moral obligation to act more widely than the advancement of their own field of research. This is fully consistent with the thinking of von Humboldt and his contemporaries cited earlier, in according to a sense of social or societal responsibility, central to the conceptualisation of what universities are for.

To summarise our argument so far, travelling and flying by academics raises questions about what academic knowledge and/or expertise are in the first place. We have expanded the question: 'Why should academics collaborate over distance?' to 'What is it about scholarship (Erkenntnis) that makes it relevant for different views in different places to encounter each other and be influenced by the encounters?' Mutual recognition and challenge serve a constitutive role. Maintaining international communities of academics and their interrelating strengthens independence from political influence. Such independence is vital to the institution of the university, as is taking ethical responsibility for the consequences of our actions as academics. Challenging travel is necessary and requires individual and collective effort.

Given the necessity of research collaboration then, with all its facets: Could collaboration simply go online to save travelling?

\section{Beyond 'Technical Solutions': Geographies and Materialities of Digital Presence and Absence in Collaborative Research}

Merely substituting one communication channel for another, treating 'going online' as a simple issue, misses out on the real effects of real materialities, including digital. Further, it misses the point on the sociality of the material and how the two are intertwined. In this section, we explore 
some of the socio-material conditions for academic collaboration in Northern Europe.

In a geographic sense, presence indicates that we are in the same room, we see each other's actions and hear each other's voices without mediation. Subtle body language (such as quiet focus vs. restlessness), variations in voice intonation and so on are consciously or unconsciously part of the picture as contributions to the many sources of feedback, which feed (or not) our impression that we are developing mutual understanding with each other. Absence here means not in the same room; not able to take part because not within earshot. Presence and absence are imbued with material conditions and with ideas about materialities (such as the degree to which an academic in his/her work is expected to have/be a body or whether the ecological footprint of our work is a relevant concern). While in daily discourse the material conditions and ideas about them are conflated and appear hardly separable, insisting on a distinction opens a space of possibilities for altering technologies and thinking differently about purposes and potential future designs (Beck, 1997).

Geographic notions of presence and absence highlight that distance does matter. The current plethora of technologies aimed at bridging geographic distance (from buses through video conferencing to Mixed Reality systems), rather than obliterating distance, testifies to its troubled and troubling nature. One way of bridging geographic distance is to remove it by moving our bodies - that is to travel. In our work as academics, we catch buses to committee meetings, and we take trains to present papers at conferences. Place and its differential usage are intertwined with privilege, as social geographers are well aware (see, e.g. Harvey's influential Spaces of Global Capitalism (2006) and papers in the journal Gender, Place and Culture, including Koskela (1997)) and travel between places very much so. A second way of bridging geographic distance is to send 'travelling' something other than a body - a text, an image, sounds - in other words, mediated contact. In a simplistic (and dominant) discourse, after the initial effort of learning the nuts and bolts of a technology, matters are apparently straightforward for the user-or so the story goes. You see me on your screen, or you do not; the sound quality is sufficient to understand what is being said, or it is not. However, bodies not-in-the-same-room, voices mediated rather than heard directly, 
contextual details not shared-these markers of non-colocation do make a difference. Systems designed for distributed professional collaboration aim to minimise the disadvantages.

To facilitate some sense of presence when not physically co-located, for example during an online meeting, an extensive infrastructure is needed. As infrastructure, its duty is to remain hidden: ${ }^{4}$ Ideally, the technical setup runs so smoothly, and the participants are so used to how it works technically and how to adjust their habits to make it work socially, that during the online encounter, only minimal attention needs to be paid to the necessary sociotechnical adaptations. However, as much research within socio-material approaches and computer-supported collaborative work (CSCW) has shown, achievements such as this requires a host of sociotechnical issues to have settled: technology choices, technical protocols for the processors to communicate with each other, people to oversee and maintain the technologies, money to buy licences, network capacity, a reliable electricity supply and so on. (For an early classic and a summary of general problems in video communication, see Heath and Luff's (1992) study of video meetings; for a recent paper including a concise summary of relevant findings in the field of CSCW, see Saatçi et al. 2020. For an impression of some socio-material approaches generally, see e.g. Law, 1991; Star, 1992; Haraway, 1997.)

A closer look at experiences of use reveals the hybrid nature of the virtuality of a video meeting itself: I materially adjust my chair so you can see my face on your screen. You try moving to a different room in your house to improve bandwidth. Meanwhile, outside our attention some algorithm is continuously monitoring sound quality, calculating estimated quality losses in sound (and picture) and altering the values of parameters such that sound legibility is prioritised above evenness of speed and completeness of image transmission. Thus, a complex mix of alignments, including automated/algorithmic and humanly performed adjustments, is necessary for the technology to apparently simply work.

In the work to make the network work, there are layers of infrastructure, generations of sociotechnical development and hours of socialising about annoying features and their fixes plaited together into (and coconstituting) the event. Over time, those of us sufficiently privileged to experience hiccups and the resolution of some of them will learn, thereby 
performing what Leigh Star and Anselm Strauss (Star \& Strauss, 1999) might have called the invisible work to make the socio-material technology work.

Materialities-physical things (including living bodies) and ideas about them-permeate practices and perceptions of technology, infrastructure and geography. They shape and are shaped by social and political habits, expectations, will to earn money, will to exercise power and much more.

For analyses of materialities as part and parcel of (work) life, we draw on what is currently known as socio-material approaches. The term loosely refers to a set of theories/methods (the conventional separation of Method from Theory is in these approaches frequently contested) that analyse technologies and human activities, ideas and so on, as not only interrelated but closely interwoven into networks. Taking a closer look at technologies and technology-human constellations that frequently are taken for granted is often termed 'opening the Black Box' (e.g. Star, 1992; Winner, 1993). In earlier days, the social construction of technology was the focus (for a critical introduction for outsiders, see Winner, 1993). Later, the scope broadened including examining ways in which science and technology are intertwined with commercial interests in worldscreating ways (for a powerful, influential and early analysis, see Haraway, 1997).

Some of the conditions for the material aspects of academic life are commonly 'Black-Boxed', that is treated as givens and not to be discussed. Such erasures form a necessary part of the hegemony of a specific form of response to the need to reduce travel: The impression that as scholars, we do not need to change our habits much, only to switch to video conferencing. In its simple form, such an argument implies, assumes, and co-creates technological 'solutions' as neutral, a narrative which the authors contest. ${ }^{5}$ Rather, we are inspired to return to von Humboldt, Schleiermacher, Fichte, and Walter Benjamin and raise questions about the deeper meanings of scholarly activity. ${ }^{6}$

Exploring the materialities of presence and absence reveals the material dimension as non-trivial; we cannot point to presence as simply being, simply existing. Rather, social and material contexts are already part of (ideas of) geographic, physical, and other kinds of locations, and 
furthermore cannot be cleanly separated from them. Many scholars are currently learning not only ways of using various bridging technologies but also ways in which we can start taking them for granted. There is a dual play of (awareness of) a range of conditions - including material, cognitive, emotional, geographic, expectational-that are necessary for the benefits to be reaped, and the simultaneous erasure of many of them. Which conditions, efforts and consequences receive continued attention, and which get routinely downplayed, impact what can readily be thought about them and through them. Therefore, 'thinking them whole' can help to create conditions for imagining new constellations of sociotechnology in the service of deeper purposes-what we previously (Beck, 1997) have termed techno-responsibility.

Splits between the social and material, body and mind (and feelings), and present and absent, are commonly perceived as dichotomous (i.e. either-or). This dichotomisation is destabilised upon close examination, as while such divides may have analytical and practical uses, they do not hold up to scrutiny when applying the lens of daily experience.

As the dire implications for the Earth of a culture of easy travel awakens a search for alternatives, contemporary technical solutions such as video conferencing technology move in purporting to fill the gap between the wish to connect and the wish not to travel. There is cause for critical caution when in this move there is scant differentiation between marketing ('buy this gadget' or licence) and ethics ('save the world'). Thus, it is possible to believe that both are well aligned with looking after the Earth-therefore, critical inquiry must dig deeper.

An understanding of the socio-materiality of presence and absence can help to widen our thinking and imagination towards better solutions. These need to be based not just on how to facilitate communication when we are physically separate, but what various meanings are served by research collaborations, and further: to understand some of the consequences of technology choices, their ecological footprints, and their limitations in how they commonly are imagined.

For example, von Humboldt, Schleiermacher and Fichte took for granted location-based institutions in a way which scholars no longer can. Today, issues of place and institution are highly complex as scholars may live in one city or country and work in another; institutions establish 
themselves in different cities and countries than their origins and names would indicate and network and virtual universities are being established. Such destabilisation of universities as location-based may on the surface be conducted in the name of freedom of thought, freedom of learning and spread of 'best practice'. The underlying logic, that with network technologies location does not matter, can be hard to counter today when this view is heard in many contexts. The ideals for scholarship discussed earlier, however, add clarity: Moves such as establishing non-local degree programmes are typically made for the competitive advantage of an institution, not for joint development of Erkenntnis. When, for example, students are located in widely different geographic locations they are treated as recipients of knowledge decontextualised from their local communities, and they have scant chance to influence that.

As for scholarly collaboration, the personal experience of the authors includes living a modest version of the distributed university: living in one city, working in another. While it is a privilege to be able to do so, the weakening of the connection to the local places (both those of living and of working) is problematic and remains so over time. This appears, for example, in the mundane details of small talk (e.g. what kindergartens the colleagues relate to), and hearing when a colleague goes to lunch; in other words, a weakening of the sense of shared experience. As we have previously documented (Beck \& Bellotti, 1993), successful research collaboration across distance can include substantial effort to establish and maintain a sufficient sense of shared experience.

While networked and non-localised universities are considered innovative for destabilising their geographical and cultural base, the weakening of ties to locations also creates a problem which requires effort to address. Further, while early institutions for educating over distance, such as the Open University in the UK, were founded on an ideal of outreach, we see no evidence of challenges to competition between universities, or to institutional ownership of knowledge in these recent developments. Rather, these developments operate within and seem to repackage interinstitutional competitiveness in complex ways. An understanding of the ideal of Erkenntnis supports such critical questioning through its insistence that scholarship worth the term cannot be limited to specific 
academics, institutions, or socioeconomic/political power structures and interests.

In summary, what is needed for us academics to travel less, shorter, and more slowly, remains a key and urgent issue. An apparently simply practical question such as whether to travel opens a host of questions about surface versus depth and ideals versus realities. Applying the Humboldtian ideals of Erkenntnis helps to maintain a focus on scholarly responsibility beyond an institution, thus rendering academics accountable to a greater context than our academic specialties.

The argument of von Humboldt, Schleiermacher and Fichte for scholarship to serve the ethical improvement of humanity, however, is insufficient for its lack of platform to the Earth and its non-human inhabitants. The next sections explore how we, as scholars, might create better alternatives.

\section{Building Understanding: Three Questions for Increased Awareness}

Our initial concern in this chapter-to understand why academics fly to various places and how we could do so less or not at all-leads us to the above examination of the purposes of distance collaboration, and why switching to mediated presence is not a simple solution as often thought.

How to act on this? First, consider the complexities of ordinary experiences of distributed collaboration. The following is a real-world example from a hybrid research meeting, that is, with some participants physically present and others present by video link (retold with permission):

In August 2020, four researchers at separate geographic locations were waiting for a hybrid research group meeting to start. None were able to connect to the virtual meeting room at the agreed time. A brief exchange of emails ensued as they tried to understand what was happening, kept each other informed, and cracked and responded to a joke combining tech. vocabulary with Covid-19 precautionary instructions. One person recontextualised a previously erroneous cancellation notice which in light of the current non-communication was perhaps not an error after all. Meanwhile, 
we (the 'in-presence' participants) could not log on to the computer in the allocated physical meeting room. This took 10-15 minutes to resolve. First, to work out why we couldn't log on (technical support was not available because they were working from their homes); after a while we surmised that we probably had a flat battery on a keyboard. Second, to look for alternative solutions inside the physical room and give that up; and third, to go down the corridor in search of another physical meeting room. Only after we found an empty room and were able to log on could the 'non-physicals' be told that the meeting simply was delayed for technical reasons, and that for the same reason we had not been able to let them know.

Here, one tiny flat battery not only spoilt a smooth start to the meeting, but made inroads towards denting the institution of the regular meetings. The required patience, which enabled the meeting to eventually happen despite this start, was sustained by the will to meet each other and to consider the actions of others as probably being reasonable (in a word: trust). Thus, while the cause of the problem was technical, the core problem was relational: The lack of explanation for the wait (not the wait itself). The case exemplifies the intertwined nature of the social, the material and the academic. Simple conceptualisations of just connecting do not capture the socio-material complexities involved in starting a meeting with a flat battery. Relational perspectives, however, do not separate human from technology to start with but rather destabilise simplistic technology-human divides. In this case, the technology worked (i.e. worked sufficiently well for its purposes) because human patience and trust made it work; also, the humans could conduct their work because the technology (eventually) facilitated it.

Why insist on the permeability of the human-technology divide? Because if humans - including scholars - co-constitute sociotechnology, then we can alter it. This is a key insight for the possibility of realising the deeper purposes of scholarly collaboration while staying within the capacity of the Earth. Choices scholars make about travel are influenced by and manifest structural conditions. While this might explain why we do not yet see a change on a larger scale, it is time to make connections between analytic understanding and actual changes of habit. In this section and the next, we cut across epistemic differences to propose a set of questions 
as signposts in the landscape, to help generate new thinking. We start by developing an understanding of the present situation, and then in the next section, we consider how to realise changes. To develop mutual understanding of the present situation, we find three questions to be helpful:

(a) What are the purposes of collaboration?; (b) What are the conditions and the various material constellations for collaboration?; (c) What are ways in which power structures embedded in existing ways of acting and thinking serve to maintain the status quo?

In more detail:

(a) In order to impact the flying habits of academics, we must consider more closely what are the purposes of research collaboration in general and in specific cases. As an individual and together with potential collaborators, we have to address this on multiple levels: What are the immediate purposes? What are the deeper purposes? And what are the long-term consequences? Furthermore: How do these relate to what I/we want for our lives and those of other humans and non-humans? At times, we may have an urgent need to meet up with distant collaborators to better understand the other's points of view. With reduced face-to-face-meetings with collaborators, how do we address collaboration issues and mutually develop new perspectives?

Some recent and potentially strong drivers of travel are tied-in with superficial (easily countable) ways of evaluating academic work. This touches on questions about internal power structures concerning the maintenance of specific forms of knowledge as being academic, the requirements for gaining recognition in academia and the role of an institution such as the university in society. Career recognition or promotion at times explicitly includes extensive international travel, for example, when applying for a grant from the European Research Council. ${ }^{7}$ Thus, any ambition to reduce the propensity to travel would need to address the criteria for assessing expertise. Subsequently, there is a need to identify and alter criteria that assume travel and replace them with criteria more 
appropriate to the complexity of the dual needs of continued international collaboration and reduced travel.

Discussing such issues not only can help to build understanding among collaborators but also, importantly, to cultivate communities of practice which consider ethical considerations to be part of academic work. Paying more attention to deeper purposes than countable outcomes may inspire more creative constellations of human and nonhuman, including the development of new sociotechnologies to support distributed research collaboration in rich ways unimaginable today. This can, and we believe ought to, have practical consequences for academics' flying.

(b) As considered earlier, technologies such as video conferencing systems do not bridge 'the gap' between physically separated persons, so much as they create conditions for specific kinds of gaps being seen as bridged, while leaving open other gaps. There is a need to examine ways in which sociotechnical solutions co-constitute (influencing, inhibiting, enhancing etc.) knowledge sharing/development of Erkenntnis in research communities. This includes attention to subtle aspects of presence as well as what it means to develop Erkenntnis with others.

If I choose to use video conferencing to reduce my impact on the Earth, I may wish to calculate the ecological footprint of the computer infrastructure involved for a comparison. At one level, this is a technical question-but not straightforward (e.g. do we assume the technology is already there, or do we include a proportion of the resource use when making and disposing of computer equipment, and the electric power consumption when using it?). At another level, why is the consideration of total resource usage so invisible in the public discourse? At this level, the simple initial question opens up a whole world of sociopolitical issues such as dominant discourses and the powers of multinational corporations.

When a choice of tools for online collaboration is made, also a set of requirements are received which — through what is readily supported and what is not-condition what is possible to do, how and by whom. The invisible work of making ourselves align with such conditioning is one ingredient in why online collaboration is a complex relational achievement, including new habits of body and of mind. 
The design choices addressing technical issues (such as for access, interruptions, reliability, back-up systems) manifest communication structures and formations beyond the situation of design. For example, solutions and support coded into the systems serve to reproduce, solidify and thus amplify culturally specific ideas of human communication. In video-meeting tools, participants are often provided with their own image on a screen, presumably to facilitate our giving of visual markers of being important. Yet, when we meet face to face, the meeting room rarely has a mirror. Thus, this feature constructs self-surfaceness, that is, the intersection between self-centredness and attention to surface features. ${ }^{8}$ This is not only a distraction but it also subtly affects the meaning of the meeting. In contrast, the non-mirror of the physical room supports a continuous focus on the issues at hand. As such, it embodies the collective insight of generations of academics.

(c) Closely related to (b), technical solutions often perpetuate established structures of power and dominance-perhaps for the simple reason that their development requires financial and other resources. Thus, mediated presence is far from neutral. Rather, it is co-dependent with (and consumes) aligned behaviour. It can easily ingrain habits, skew preferences in the formal structures for recognition of academic work, and entrench a lack of inclusiveness for non-dominant groups of humans, animals, plants and the well-being of the Earth.

In and through the new features, some previously naturalised achievements (such as how the small talk of people gradually arriving and leaving a meeting room can help to establish an atmosphere of mutual interest in each other or a lack of it) are no longer to be taken for granted, and new ones must be constructed-in other words collectively woken up to, painstakingly cultivated and at times fought for.

Online collaboration is as relational as any other collaboration, yet the question of which kinds of relational work are supported and which are not, are marked by familiarly stratified (in)visibilities. For example, talking heads (a screen image showing our faces and little else) are well supported, but not the informality of key forms of interactivity, since the video conferencing technology typically constrains one person to speak at a time. This is helpful for clarity, for low bandwidth conditions and for listening in conditions where strictly structured turn-taking is 
appropriate (as in most formal and semi-formal meetings, and in some but not all conversations). One person speaking at a time is good for listening to speech but not good for singing or laughing together (the technology cuts the sound from one person or the other), nor for music (the sound managing algorithms may cut low or high notes as being noise). Impulsive feedback, such as sounds (interjections) indicating agreement or disagreement, get caught in a binary either-or: Either your sounds are filtered out and not transmitted, or they are loud enough and of the right characteristics (calm human voice) that the Speaker role is transferred to you. This is carefully designed to serve conventional meetings, which translates as meetings within culturally dominant communities in the US. ${ }^{9}$ Further and importantly, experience to date from teachers in higher education indicates that achieving a sense of shared participation from a group of, for example, 50 students is harder to manage online than when co-located. When in the same room, the lecturer sees not only explicit gestures (raising of a hand) but also receives subtle feedback about levels of attention, including from body language.

The technologies come parcelled with assumptions about specific ways of being together which are supported over others, that is they are recreated and reproduced. Specific views of the landscape are afforded which obscure other views; just as the introduction of gondola cable cars on a hillside would not only increase the speed of ascent but would forever alter the meaning of ascending that hill. The functionality offered may or may not fit the various needs of academic collaboration for research, teaching and so on and will alter those needs.

While our habituation as academics towards extensive travel renders many of its troubles culturally invisible-un(ac)countable (i.e. absent from accounting) — they have not disappeared. Until recently, money and visas may have been the principal limiting factors; now, environmental impact is an urgent reason for everyone to travel slower or not at all. The COVID-19 pandemic provides an interesting example: powerful, affecting deeply rooted cultural and individual habits — with unpredictable (especially during the initial months) and potentially lethal consequences. The response has seen populations across most countries change daily habits (including travel). This is a major achievement due to the involvement of innumerable bodies from governments and international 
NGOs to changing habits of friendship. We ought to ask why no similar wholesale approach has yet resulted from the cry of the young-and the cries of our colleagues the Climate and Biological Scientists and Social Geographers_-about the future of humankind and other species? Yet, no redistribution of power, wealth or health impacts has yet been asked of us. Why not?

Having proposed and applied these three questions for understanding the complexities of the present situation, we next ask how we can develop ways of challenging or changing existing structures deemed unhelpful.

\section{Action and Commitment to Change}

The Earth has its own language of suffering and is speaking to us right now-rising average temperatures, increasingly extreme weather conditions, mass extinction of species. Whether or not we want to use a language of love of the Earth, the dependency remains that the Earth needs humans to listen better and act differently for its well-being, and humans need the Earth to continue to provide with sufficient stability air, water, food, shelter and the other foundations for life as we know it. Ignoring human dependence on (or interdependence with) our social and natural environments has mounted to problems of a massive scale, for example as reported to the United Nations Summit on Biodiversity on September 30, 2020. ${ }^{10}$ The Introduction to the summit sees the need for 'leadership and commitment to improve our relationship with nature, addressing the causes of change, and ensuring that biodiversity and the contributions it provides to all people are at the heart of sustainable development and the fight against climate change' (United Nations, 2020).

The above reading of von Humboldt's, Schleiermacher's and Fichte's conception of the university as an institution that strives for the good of humanity, reminded us of the need for scholarship to remain in a certain sense responsible for-and responsive to-society. Their work was pivotal in establishing a direction for the academic community as an exercise in ethical commitment, starting a tradition for thinking of the value of collaborative academic work. What are the deeper purposes of academic collaboration remains a not-settled question, just as it should be. As 
argued earlier, it includes Erkenntnis and importantly also collaboration as a counterweight to competition, including sharing insights and evolving academic understanding for the benefit of all. Still, who all are, needs to transcend the anthropocentric roots of the Humanism from which this view originated. Thus, the original ideal of von Humboldt, Schleiermacher and Fichte that scholarship should serve the ethical improvement of humanity remains important but no longer suffices. To build on and expand such notions, we turn to more recent European thinking and ancient Asian wisdom.

As human beings, we do not individually choose whether or not to be in relation to others; we constitute our individual being out of the relation with and the presence of each other (Lévinas, 1999; Løgstrup, 1992). ${ }^{11}$ Zen Master Thích Nhất Hanh extends this thinking to nonhumans with the term interbeing (Nhất Hạnh, 1998). The idea of interbeing highlights the insight that 'we cannot be without interbeing. ${ }^{12}$ Humans depend on and are co-constituted by other beings, including living beings (such as humans) and non-living beings (for example, the Earth, the air etc.). A simple example explains the concept: To fill a glass of drinking water from my tap, I depend on clouds and rain, on rivers and lakes. I further depend on irrigation systems, waterworks, extensive networks of pipes and on sewage processing. Further, on the engineers and workers who planned, built and are maintaining these systems. This includes their education and practical training, and the municipality which oversees those waterworks, the taxes paid which provides the municipality with the means to do so and so on. The analysis of the contributing conditions can be conducted endlessly broadly-because everything inter-is. How to make use of the insight of interbeing is a question less of principled truths than of practical wisdom. Thus, ethical choice enters also from this perspective.

Importantly, the concept of interbeing highlights the interconnectedness of not only all living beings but also of the non-living. While this notion of interconnectedness appears radical, it provides terminology for naming an already experienced reality of human life subject to weather changes, the grief of mass extinction of species near and far and so on. Such experiences, widely under-acknowledged including in academic discourse, need to be conceptualised to support articulating and 
sense-making of their impacts on habitual ways of relating to humans and non-humans.

A lack of examining what is at stake when switching to video testifies in our view to the salience of at least two issues: a paucity of reflection beyond a need to bridge distance and its technical satisfaction, greatly afforded by the persuasive 'quick fix' language of technology marketing; and a willingness to grasp at simple conceptualisations. The former has been discussed above; the latter may for many researchers and teachers be facilitated for example by sheer exhaustion from dealing with complex layers of systems (administrative, technological, various accountability systems etc.) on the surface of research and teaching (Berg \& Seeber, 2016).

Specifically, the (ethical) intention of altering behaviour that suffocates the planet, places under question collaboration across geographic difference (as discussed earlier, including whether to, for what purposes and how to); the possibility and necessity of shifts in the differentials of power and privilege (what is equity between humans, and between humans and non-humans; and how to work towards it); and the frustrations of succumbing to the narrowly designed worlds of bridging technologies (can other choices be developed? Could speculative conceptualisations of new purposes towards which technologies might be designed (Beck, 1997) include Erkenntnis and social responsibility?).

To move wisely through such landscapes, we authors suggest that as academics and as citizens, we need to overcome our own resistance to new habits. For example, the previous obstacles to unchecked travel were impacting unevenly, depending as they did on the capacity to muster resources such as money and time. They were effective in reproducing an uneven distribution of privilege, which may have been their deeper purpose (cf. arguments by Harvey cited above and Manuel Castells [e.g. 2000], about the necessity of uneven geographic development to secure the interests of élites). Because of habituation into accepting uneven distribution which leaves some in abject poverty and others over-using resources, a shift in collective consciousness into taking responsibility for depleting non-local (natural) resources is needed. Doing so may turn out to be no less satisfying for our deeper needs.

A key in this endeavour for us academics is commitment; both a willingness to pay closer attention to the conditions and needs that surround 
us and a willingness to establish new habits. The purposes of our collaborations could beneficially be reflected upon in light of commitments to other people (colleagues, but also communities outside the university); to the geographical places in which we are working, doing research and sharing our scholarship; and, further, to relations and places further away (geographically and conceptually).

Thus, as newish technologies have been ushered in to rescue people from (fear of) COVID-19-piggybacking the worlds-making powers and the specific forms of presences and absences that the technologies afford-it is the surface-ness that draws substantial amounts of attention. There is an unexamined tension between wanting the technology to recede into mere infrastructure (for it to be, so to speak, merely a 'Boring Thing $\left.{ }^{13}\right)$, and the frequent experience of its refusal to comply with the dreams promised, resulting in much frustration. Such frustration at the sociotechnological 'solutions' we authors view as an individualised manifestation of structural problems at the base of which is the maintenance of difference (as discussed earlier).

Having some understanding of the need for change, questions arise about how to proceed. Specifically, how can academic communities develop ways of challenging or changing existing structures deemed unhelpful? And how might new (socio-material) systems be developed from different stances? For transforming academics' habits of flying, much material-relational (re-)working, un-learning, and re-learning is required, both by individuals and not least from the systems of recognition within which they/we work. Might scholars extend analyses such as these and develop new kinds of theories and practices based on the wisdom of interbeing, or radical interconnectedness?

While the magnitude of the necessary change may for some seem insurmountable, for us a lesson from the COVID-19 responses and the evidence of success in slowing down the spread of the virus is that when there is a willingness among sufficient numbers to pull in the same direction, substantial changes can be made in a short time. To change from mustering resources to protecting resources, as discussed above, the key learning may need to happen among those who have been habituated into believing we/they could do as they wanted, yet now are having to desist. 
Changes in habits of collaboration then, such as travel, not only entails a technical change of communication channels but also involves ethical work, such as reopening questions of commitment, and structural/political critique and change. In short, in the necessary transformation of academic collaboration to become compatible with responsible cohabitation on and with the Earth, work is needed to (re)create conducive conditions for the interrelational purposes of collaboration in new forms. These include technical solutions and calculations of ecological impacts, but importantly also, strengthening a sense of interbeing between not only our peers but also with non-academics, with humans of the future, with other species, and with the Earth itself.

But how to change? The cultural habit of not looking after ourselves by not looking after the needs of the Earth includes our relation to change. We (the authors) claim that in our contemporary culture, change is commonly assumed to be manageable; culturally 'we' 'should' be able to control change (through planning, innovation and managing it well). Based on distinguished development work on leadership within the United Nations, Monica Sharma (2014) sounds an alert about established 'Blueprints for change' (i.e. ways of leading) and argues the need for new approaches. Transformational change requires not only attention to instrumental and systemic issues, but also self-discovery (Sharma, 2007) and trust in the innate wisdom of people (Sharma, 2014). Based on her practical experience, Sharma's 2014 model for a new blueprint provides a relevant framework for the work of change called for in this chapter.

Thus, change is possible. It is already taking place; it is here for us to join.

\section{Notes}

1. Such messengers include temperature changes, erratic winds, wild animals intruding into human territory for lack of their own, species extinctions and so on.

2. We see a parallel to this insight in the decentralisation of universities that took place in many Western countries during the 1970s and 1980s. Higher education was provided on smaller campuses in more rural areas 
in order to extend the accessibility of academic knowledge to a wider range of environments.

3. Haraway's (1991) term 'situated knowledges' is the source of our use of the plural 'knowledges'.

4. Absent from awareness, that is, absent from ethical presence.

5. The environmental impact of using (building, selling, running) computational technologies is itself a topic worthy of study.

6. Inspired by the quest of Walter Benjamin (1955/1999) for the deeper purpose of translation and our previous application of Benjamin's question to the deeper purpose of science (Beck, 2016). Further, we are inspired by Haraway's (e.g. 1997) 'diffractive' analysis of technoscience.

7. As of 2020.

8. So key is this feature that in the Zoom video conferencing system, toggling Show/Hide Self-View is currently (November 2020) one of the few functions accorded its own button.

9. This claim is based on the personal experience of one of the authors from years in such cultures.

10. Assessments by the Intergovernmental Science-Policy Platform on Biodiversity and Ecosystem Services (IPBES) included that: 'Nature across most of the globe has now been significantly altered by multiple human drivers, with the great majority of indicators of ecosystems and biodiversity showing rapid decline. Seventy-five per cent of the land surface is significantly altered, 66 per cent of the ocean area is experiencing increasing cumulative impacts, and over 85 per cent of wetlands (by area) has been lost.' Further, 'The average abundance of native species in most major terrestrial biomes has fallen by at least 20 per cent, potentially affecting ecosystem processes and hence Nature's contributions to people; this decline has mostly taken place since 1900 and may be accelerating' (IPBES, 2019, both quotes p. 11).

11. For a closer discussion of this claim in education, see Schaffar (2014).

12. Personal communication, ca. 1996. Thích Nhất Hạnh has repeated the phrase in numerous public talks. For a closer look at meanings of the term and practice of Interbeing, see, for example, Nhất Hạnh (1998). For an exploration of Levinas and Nhất Hạnh sensitive to 'Western' and non-Western perspectives, see Ucok-Sayrak (2014).

13. Sociologist of Science and of infrastructure S. Leigh Star used to say she wanted to start a 'Society for the Study of Boring Things'. 


\section{References}

Beck, E. E. (1997). Managing diffracted rationalities: IT in a home assistance service. In I. Moser, \& G. H. Aas (Eds.), Technology and democracy: Gender, technology and politics in transition? Research report TMV Skriftserie 1997-29 (pp. 109-132). University of Oslo, Centre for Technology, Innovation and Culture.

Beck, E. E. (2016). Thundering silence. On death, fear, science. In G. C. Bowker, S. Timmermans, A. E. Clarke, \& E. Balka (Eds.), Boundary objects and beyond. Working with Leigh Star (pp. 435-457). MIT Press.

Beck, E. E., \& Bellotti, V. M. E. (1993). Informed opportunism as strategy: Supporting coordination in distributed collaborative writing. In G. De Michelis, C. Simone, \& K. Schmidt (Eds.), ECSCW '93. Proceedings of the third European Conference on Computer-Supported Cooperative Work, 13-17 September 1993, Milano, Italy (pp. 233-248). Kluwer Academic.

Benjamin, W. (1999). The task of the translator. In W. Benjamin (Ed: Arendt, H.), Illuminations (pp. 70-82). Pimlico.

Berg, M., \& Seeber, B. K. (2016). The slow professor. Challenging the culture of speed in the Academy. University of Toronto Press.

Castells, M. (2000). The rise of the network society. The information age: Economy, society and culture, Vol 1. Blackwell.

Fichte, J. G. (1807). Deduzierter Plan einer zu Berlin zu errichtenden höheren Lehranstalt. In Habekost, E. (Ed.), Gründungstexte. Johann Gottlieb Fichte, Friedrich Daniel Ernst Schleiermacher, Wilhelm von Humboldt. Festgabe zum 200. Jubiläum der Humboldt-Universität zu Berlin. Berlin 2010. Retrieved October 28, 2020, from http://edoc.hu-berlin.de/miscellanies/g-texte-30372/ all/hu_g-texte.pdf

Haraway, D. J. (1991). Situated knowledges: The science question in feminism and the privilege of partial perspective. In D. J. Haraway (Ed.), Simians, cyborgs, and women: The reinvention of nature (pp. 183-201). Free Associations Books.

Haraway, D. J. (1997). Modest_Witness@Second_Millenium. FemaleMan ${ }^{\odot}$ Meets_OncoMouse ${ }^{\mathrm{TM}}$. Feminism and technoscience. Routledge.

Harvey, D. (2006). Spaces of global capitalism: Towards a theory of uneven geographic development. Verso.

Heath, C., \& Luff, P. (1992). Media space and communicative asymmetries: Preliminary observations of video-mediated interaction. Human-Computer Interaction, 7(3), 315-346. https://doi.org/10.1207/s15327051hci0703_3 
IPBES. (2019). Summary for policymakers of the global assessment report on biodiversity and ecosystem services of the Intergovernmental Science-Policy Platform on Biodiversity and Ecosystem Services. S. Díaz, J. Settele, E. S. Brondízio, H. T. Ngo, M. Guèze, J. Agard, A. Arneth, P. Balvanera, K. A. Brauman, S. H. M. Butchart, K. M. A. Chan, L. A. Garibaldi, K. Ichii, J. Liu, S. M. Subramanian, G. F. Midgley, P. Miloslavich, Z. Molnár, D. Obura, A. Pfaff, S. Polasky, A. Purvis, J. Razzaque, B. Reyers, R. Roy Chowdhury, Y. J. Shin, I. J. Visseren-Hamakers, K. J. Willis, \& C. N. Zayas (Eds.). IPBES secretariat. Retrieved October 28, 2020, from https://doi.org/10.5281/ zenodo.3553579

Koskela, H. (1997). 'Bold walk and breakings': Women's spatial confidence versus fear of violence. Gender, Place \& Culture, 4(3), 301-320. https://doi. org/10.1080/09663699725369

Law, J. (Ed.). (1991). A Sociology of monsters. Essays on power, technology and domination. Routledge.

Lévinas, E. (1999). Die Spur des Anderen. Untersuchungen zur Phänomenologie und Sozialphilosophie. Alber Studienausgabe. Verlag Karl Alber.

Løgstrup, K. E. (1992). Det etiska kravet. Daidalos.

Murdoch, I. (1997). Existentialists and mystics. Writings on philosophy and literature. Penguin Books.

Nhất Hạnh, T. (1998). Interbeing. Parallax Press.

Saatçi, B., Akyüz, K., Rintel, S., \& Klokmose, C. N. (2020). (Re)configuring hybrid meetings: Moving from user-centered design to meeting-centered design. Computer Supported Cooperative Work (CSCW), 29(6), 769-794. https://doi-org.ezproxy.uio.no/10.1007/s10606-020-09385-x

Schaffar, B. (2014). Changing the definition of education. On Kant's educational paradox between freedom and restraint. Studies in Philosophy and Education, 33(1), 5-21. https://doi.org/10.1007/s11217-013-9357-4

Schaffar, B., \& Kronqvist, C. (2017). Educating judgement. Learning from the didactics of philosophy and sloyd. Revista Española de Educación Comparada, 29, 110-128. https://doi.org/10.5944/reec.29.2017.17207

Schaffar, B., \& Uljens, M. (2015). Paradoxical tensions between Bildung and Ausbildung in Academia. Moving within or beyond the modern Continental tradition? In E. Westergaard \& J. S. Wiewiura (Eds.), On the facilitation of the academy (pp. 1-16). Sense Publishers.

Schleiermacher, F. D. E. (1808). Gelegentliche Gedanken über Universitäten im deutschen Sinn. Nebst einem Anhang über eine neu zu errichtende. In Habekost, E. (Ed.), Gründungstexte. Johann Gottlieb Fichte, Friedrich Daniel 
Ernst Schleiermacher, Wilhelm von Humboldt. Festgabe zum 200. Jubiläum der Humboldt-Universität zu Berlin. Berlin 2010. Retrieved October 28, 2020, from http://edoc.hu-berlin.de/miscellanies/g-texte-30372/all/hu_g-texte.pdf Schleiermacher, F. E. D. (1994). Theorie der Erziehung. In F. D. E. Schleiermacher (Ed.), Ausgewählte pädagogische Schriften. Schöninghs Sammlung pädagogischer Schriften. Ferdinand Schöningh.

Sharma, M. (2007). Personal to planetary transformation. Kosmos. Retrieved October 30, 2020, from https://www.kosmosjournal.org/article/ personal-to-planetary-transformation/

Sharma, M. (2014). Sourcing wisdom for just and sustainable results. Kosmos. Retrieved October 30, 2020, from https://www.kosmosjournal.org/article/ sourcing-wisdom-for-just-and-sustainable-results/

Star, S. L. (1992). The Trojan door: Organizations, work, and the 'open Black Box’. Systems Practice, 5(4), 395-410. https://doi.org/10.1007/BF01059831 Star, S. L., \& Strauss, A. (1999). Layers of silence, arenas of voice: The ecology of visible and invisible work. Computer Supported Cooperative Work, 8(1-2), 9-30. https://doi.org/10.1023/a:1008651105359

Ucok-Sayrak, O. (2014). Interbeing and the "Ethical Echo" of Levinas: Exploring communication ethics beyond willed agency. Review of Communication, 14(3-4), 245-269. https://doi.org/10.1080/1535859 3.2014 .986515

United Nations. (2020). Summit on biodiversity. Retrieved October 28, 2020, from https://www.un.org/pga/75/united-nations-summit-on-biodiversity/

Von Humboldt, W. (1809/1810). Über die innere und äussere Organisation der höheren wissenschaftlichen Anstalten in Berlin. In Habekost, E. (Ed.), Gründungstexte. Johann Gottlieb Fichte, Friedrich Daniel Ernst Schleiermacher, Wilhelm von Humboldt. Festgabe zum 200. Jubiläum der Humboldt-Universität zu Berlin. Berlin 2010a. Retrieved October 28, 2020, from http://edoc.huberlin.de/miscellanies/g-texte-30372/all/hu_g-texte.pdf

Von Humboldt, W. (1809). Antrag auf Errichtung der Universität Berlin. In Habekost, E. (Ed.), Gründungstexte. Johann Gottlieb Fichte, Friedrich Daniel Ernst Schleiermacher, Wilhelm von Humboldt. Festgabe zum 200. Jubiläum der Humboldt-Universität zu Berlin. Berlin 2010b. Retrieved October 28, 2020, from http://edoc.hu-berlin.de/miscellanies/g-texte-30372/all/hu_g-texte.pdf Winner, L. (1993). Upon opening the Black Box and finding it empty: Social constructivism and the philosophy of technology. Science, Technology, \& Human Values, 18(3), 362-378. 
Open Access This chapter is licensed under the terms of the Creative Commons Attribution 4.0 International License (http://creativecommons.org/licenses/ by/4.0/), which permits use, sharing, adaptation, distribution and reproduction in any medium or format, as long as you give appropriate credit to the original author(s) and the source, provide a link to the Creative Commons licence and indicate if changes were made.

The images or other third party material in this chapter are included in the chapter's Creative Commons licence, unless indicated otherwise in a credit line to the material. If material is not included in the chapter's Creative Commons licence and your intended use is not permitted by statutory regulation or exceeds the permitted use, you will need to obtain permission directly from the copyright holder.

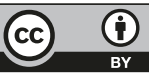

